\title{
Preparedness of Kenyan health workers to deliver HIV/AIDS services
}

National AIDS and STD Control Programme

Ministry of Health Kenya

Centers for Disease Control and Prevention

Horizons Program

Follow this and additional works at: https://knowledgecommons.popcouncil.org/departments_sbsr-hiv

Part of the Demography, Population, and Ecology Commons, Family, Life Course, and Society Commons, International Public Health Commons, and the Medicine and Health Commons How does access to this work benefit you? Let us know!

\section{Recommended Citation}

National AIDS and STD Control Programme, Ministry of Health Kenya, Centers for Disease Control and Prevention, and Horizons Program. 2007. "Preparedness of Kenyan health workers to deliver HIV/AIDS services," Horizons Research Summary. Washington, DC: Population Council. 


\section{Preparedness of Kenyan Health Workers to Deliver HIVIAIDS SERVICES}

\section{$\mathrm{K}$} nya is now acknowledged as one of the few countries that has successepidemic. According to UNAIDS (2006), nationwide HIV prevalence is estimated to be 6.1 percent among adults ages $15-49$ years, down from 10 percent in the late 1990s (MOH 2005; Cheluget et al. 2006). HIV surveillance data over the last 15 years provide strong evidence that there has also been a decline in incidence - the number of new cases appears to have peaked at 200,000 annually in the early 1990s, and to have fallen to 86,000 in 2003 (MOH 2005).

Despite these positive achievements, most Kenyan adults do not know their HIV status. According to the 2003 Kenya Demographic and Health Survey, only 14 percent of men and 13 percent of women ages 15-49 years have ever tested for HIV (Central Bureau of Statistics et al. 2004). There are now over 800 voluntary counseling and testing (VCT) and over 1,000 prevention of mother-to-child transmission (PMTCT) sites in the country, allowing more Kenyans to learn their serostatus (NASCOP/MOH 2006). Still, VCT and PMTCT services may not reach many individuals who would benefit from HIV testing and counseling, such as hospital patients. Patients who present to a health facility can benefit from learning their status as part of the di-

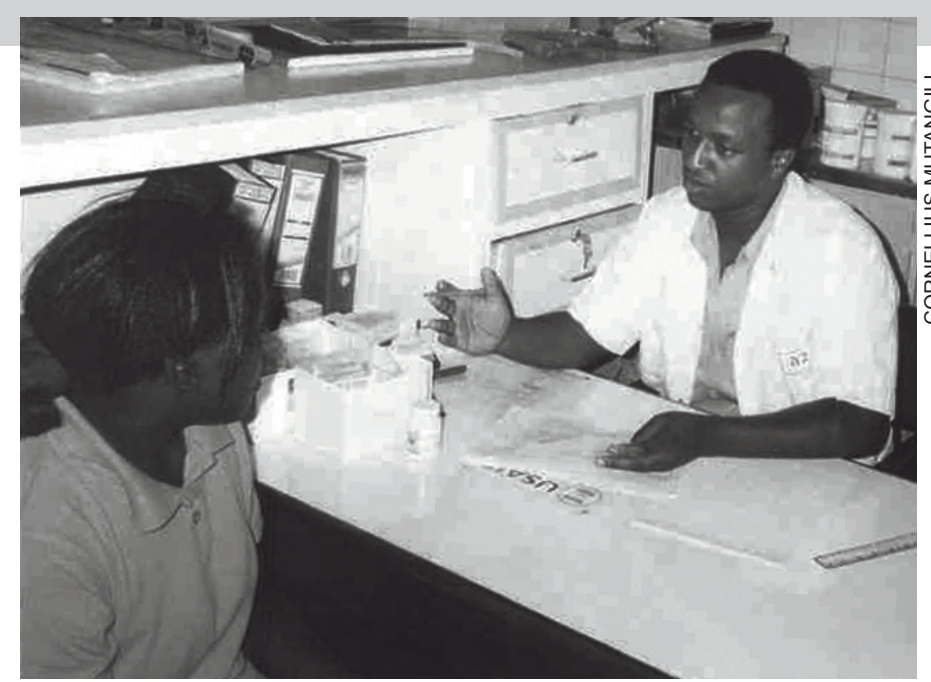

A counseling session at a local hospital.

agnostic assessment, enabling health care personnel to provide a more accurate clinical evaluation and accelerate access to comprehensive care. This is particularly relevant in Kenya because up to 60 percent of all medical ward hospital beds are estimated to be occupied by HIV-infected patients (NASCOP/ MOH 2004). Therefore provider-initiated HIV testing and counseling, which includes diagnostic testing and counseling (DTC), provides an opportunity to interrupt the cycle of HIV transmission to the partners and children of patients, thereby contributing to HIV prevention efforts.

In 2004, the Kenya Ministry of Health (MOH) launched a landmark publication, Guidelines for HIV Testing in Clinical Settings. These guidelines aim to assist health workers to provide high quality DTC in clinical settings (Box 1). In order to assess

To read more about this study, go to www.popcouncil.org/pdfs/horizons/kehwrprt.pdf 
the preparedness of health workers to provide DTC, the National AIDS and STD, TB, and Leprosy Control Program (NASCOP/NTLP), in collaboration with the Horizons Program of the Population Council and the Centers for Disease Control and Prevention (CDC-Kenya), conducted a national study - the 2005 Kenya Health Worker Survey. This study also provided an opportunity to assess HIVrelated service delivery in the country and document how HIV has affected health workers' personal and professional lives. Financial support for the study was provided by CDC-Kenya under the President's Emergency Plan for AIDS Relief (PEPFAR).

\section{Methods}

Data were collected in May and June 2005 from 1,897 health workers in 247 health facilities in all seven provinces of Kenya plus Nairobi, using a guided, self-administered questionnaire. The survey sample included health workers from public, faith-based, and private hospitals, health centers, dispensaries, and maternity homes. Health workers who worked directly with patients and were involved in HIV testing or management of HIV disease-specifically doctors, clinical officers, nurses, laboratory technicians, social workers, and VCT counselors-were selected to participate in the survey. To complement the quantitative data, focus group discussions (FGDs) were also conducted with individuals from these cadres of health care personnel and with district health management teams (DHMTs). on weighted data.

The Kenya National Council for Science and Technology (NCST), and the ethical review bodies of both Horizons/Population Council and CDC-Kenya approved the study. Prior to completing the questionnaire or participating in an FGD, each participant completed a consent form.

The quantitative data were weighted to reflect the national distribution of health workers in Kenya. All results presented in this summary are based

\section{Characteristics of the Sample}

Of the 1,897 respondents, 62 percent were female. Enrolled nurses ${ }^{1}$ comprised the largest group of health workers (44 percent), suggesting that the bulk of health care in Kenya is delivered by this group. Registered nurses comprised 21 percent of the sample. Rift Valley, the province with the most health facilities, also had the greatest number of respondents (26 percent). More than 70 percent of the respondents worked in hospitals, and 80 percent worked in public health care facilities. The mean age of the respondents was 38 years; 75 percent were currently married. Respondents had worked in their current health facility for a median of six years.

\footnotetext{
${ }^{1}$ In Kenya, there are two types of nurse cadres: enrolled and registered. Registered nurses receive more advanced training and are given greater management responsibility in a health care facility than enrolled nurses.
}

\section{Box 1 Diagnostic Testing and Counseling}

DTC is the procedure whereby a health worker requests, as part of other investigative tests, HIV testing of a patient with symptoms that could be attributable to HIV. Thus DTC is conducted in the context of medical care. When symptoms suggestive of HIV, such as tuberculosis, are present, DTC is performed routinely as a basic standard of care. The main purpose of DTC is to identify HIV in patients so that they can receive comprehensive care.

DTC uses an opt-out approach, that is, it is assumed that patients with symptoms of HIV desire a diagnosis, therapy, and care. This therefore implies consent for diagnostic testing, including for HIV. HIV testing should therefore not be treated differently from other non-invasive tests such as sputum or urinalysis or other blood tests. However, the HIV test must be conducted with informed consent; patients must be informed that the test is being done and have a right to decline.

Source: NASCOP/MOH: Guidelines for HIV Testing in Clinical Settings, August 2004 


\section{Key Findings}

\section{Providers who initiated HIV testing reported following the DTC guidelines.}

Most providers reported that HIV testing was available in their facility; only 12 percent worked in facilities that did not have HIV testing. All respondents were asked whether they had "ever ordered an HIV test on an adult patient," and 41 percent said they had done so. This represented nearly all doctors (99 percent) and clinical officers ( 88 percent), 42 percent of registered nurses, and 32 percent of enrolled nurses. The results also showed that nearly one in five laboratory staff had ordered an HIV test.

When asked about the last adult HIV test they ordered, 91 percent reported that they informed the patient themselves about the test before it was conducted, 92 percent made HIV pre-test counseling available either by conducting it themselves or arranging for it to be done by someone else, and a similar percentage made HIV post-test counseling available (Figure 1). Thus, the vast majority of providers reported following the counseling and consenting components outlined in the DTC guidelines.

\section{There is a large unmet need for training on DTC among providers.}

Among respondents who reported conducting HIV counseling or testing ( 49 percent of the sample), more than a fourth ( 28 percent) had not been specifically trained in the procedure(s) they were carrying out. This included 45 percent of doctors, 40 percent of clinical officers, 30 percent of enrolled nurses, and 29 percent of registered nurses.

While health workers overall felt confident that they could conduct most aspects of DTC, the vast majority felt that further training would provide them with important skills. For example, although the DTC guidelines encourage couple counseling, 22 percent of the study sample, including 25 percent of enrolled nurses, were not aware of the term "couple counseling." ${ }^{2}$ Once the term was clarified, 90 percent of health workers felt they needed further training in this area. In fact, couple counseling was the area of greatest demand for training. Around 80 percent of respondents also felt they needed additional training in how to recommend an HIV test to a patient and how to provide post-test counseling for both HIV-positive and HIV-negative patients. Focus group participants highlighted the value of staff training on DTC. According to one informant:

\section{All staff should be trained [in HIV counseling and testing], as this will reduce the inconvenience of referring clients to other health workers....}

Male doctor, Rift Valley Province

Health providers were generally supportive of DTC and also perceived that management was largely supportive as well, particularly for medical patients, pregnant women, STI patients, TB patients, and mothers of HIV-positive children. Some providers also noted that management had taken steps to implement DTC widely by providing staff, equipment, space, and training.

\section{Nearly two-thirds of health workers had been tested for HIV.}

As shown in Table 1, VCT counselors were the most likely to have been tested for HIV (89 percent) and

${ }^{2}$ Those who did not know what couple counseling was were read a definition and then were asked further questions about it.

\section{Figure 1 Recommended procedures followed by health workers during last adult HIV test ordered*}

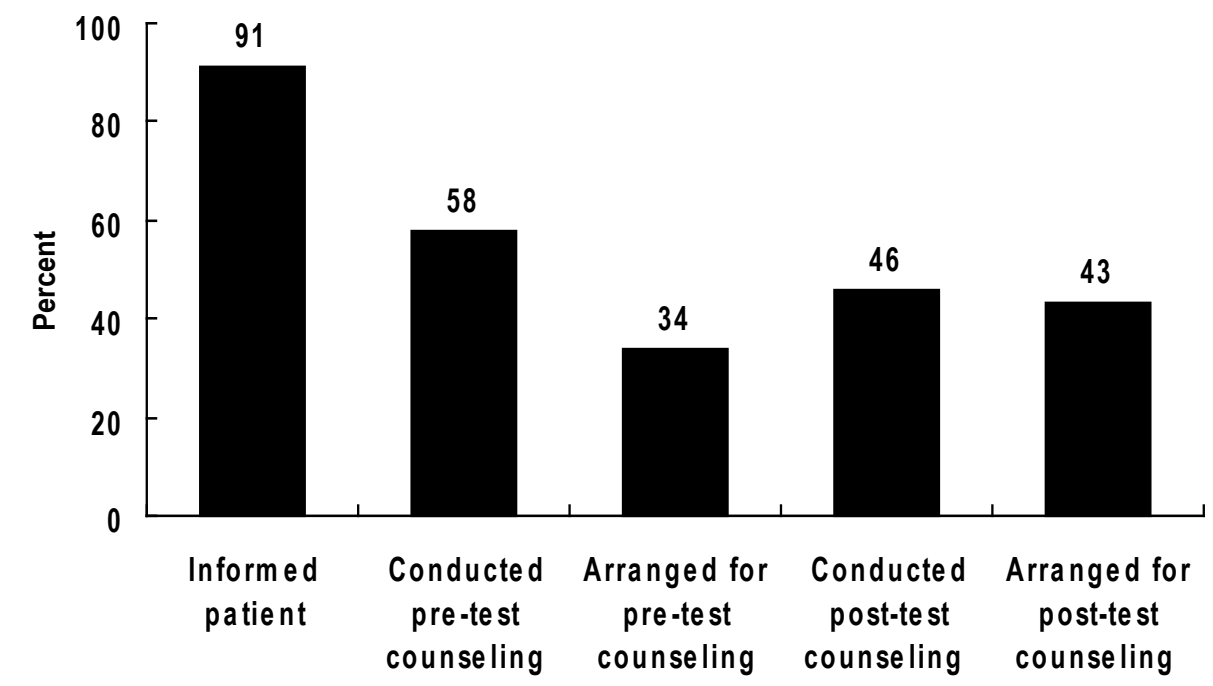

${ }^{*} n=776$ health workers who had ever ordered an HIV test for an adult patient 
enrolled nurses and social workers the least likely (55 percent and 54 percent, respectively). Over half (57 percent) of those who had been tested said they had done so more than 12 months before the survey. When asked why they had never been tested for HIV, 42 percent of untested health workers said "no particular reason," 34 percent said they did not feel at risk, 33 percent were "planning to go for the test," and 22 percent said they were afraid of the results. Overall, less than half ( 49 percent) of health workers who had a partner reported that the partner had been tested.

\section{Many health workers were interested in testing themselves for HIV.}

Nearly three-fourths (73 percent) of health workers were interested in self-testing (Table 1). When asked why, providers gave several reasons including that selftesting eliminated the possibilities of stigma and suspicion (since other colleagues would not know that the provider had sought HIV testing), guaranteed that the results would be confidential, and reduced the fear that the "test had been tampered with" because it was a "do-it-yourself" option. Others felt that the availability of self-testing kits would offer immediate benefits, such as greater acceptability of HIV testing.

It will be a breakthrough because stigma would die out.

Male doctor, Rift Valley Province

However, self-testing was not necessarily seen as a trouble-free option, and some FGD participants expressed reservations, with many feeling that lack of counseling and follow up was a drawback. Others feared abuse by health workers testing unwilling family members.

Unless you have been counseled, self-testing is not good.

DHMT member, Eastern Province

I would be scared if I do it alone... I fear to know my status if I am alone.

Female nurse, Coast Province

\section{Only a third of health workers caring for AIDS patients had received relevant training.}

Analysis of AIDS patient management was restricted to doctors, clinical officers, and nurses $(n=1,494)$. While 79 percent of respondents in these cadres had taken care of AIDS patients at their current facility, only 33 percent had received any training in AIDS
Table 1 Health workers and HIV testing

\begin{tabular}{lccc}
\hline & $\begin{array}{c}\text { Ever been } \\
\text { tested } \\
\text { for HIV^ } \\
\%\end{array}$ & $\begin{array}{c}\text { Partner } \\
\text { tested } \\
\text { for HIV^^} \\
\%\end{array}$ & $\begin{array}{c}\text { Interested } \\
\text { in self- } \\
\text { testing^ } \\
\%\end{array}$ \\
\hline Sex & & & \\
$\quad$ Male & 66 & 51 & 74 \\
Female & 63 & 47 & 72 \\
Cadre & & & \\
Doctor & 79 & 68 & 81 \\
Clinical officer & 67 & 52 & 79 \\
Registered nurse & 69 & 54 & 77 \\
Enrolled nurse & 55 & 39 & 76 \\
Laboratory staff & 76 & 58 & 77 \\
Social worker & 54 & 47 & 64 \\
VCT counselor & 89 & 70 & 32 \\
Others & 60 & 47 & 62 \\
Province & & & \\
Central & 58 & 64 & 66 \\
Coast & 74 & 53 & 72 \\
Eastern & 54 & 40 & 77 \\
Nairobi & 81 & 64 & 77 \\
North Eastern & 72 & 52 & 63 \\
Nyanza & 70 & 54 & 81 \\
Rift Valley & 62 & 48 & 72 \\
Western & 62 & 52 & 69 \\
All respondents & 64 & 49 & 73 \\
\hline Number of & 1,892 & 1,688 & 1,892 \\
respondents & & & \\
\hline & & & \\
\hline
\end{tabular}

^Among all respondents; ^^Among respondents with a partner

patient management, and only 59 percent of those with some training felt adequately prepared to undertake their assigned tasks (Table 2). Enrolled nurses were the least likely to have received any training. Regional analysis showed that in all seven provinces plus Nairobi the majority of providers specifically tasked with the management of AIDS patients had not been trained in the management of HIV disease. Indeed in no province had even half of the providers been trained.

A major problem for health workers was lack of access to guidelines and materials on AIDS management. The government has produced several guidelines to provide assistance to health workers in their management of AIDS patients. Of the eight guidelines ${ }^{3}$ that should have been read by all doctors, clinical officers, and nurses and were explored in this survey, these clinicians on average had read only four. The recently launched

${ }^{3}$ The eight guidelines are on DTC, VCT, PMTCT, antiretroviral therapy, opportunistic infections, $\mathrm{TB}$, home-based care, and condoms. 
DTC guidelines had been read by only a fourth of clinicians surveyed.

\section{Few providers surveyed felt that HIV-infected patients receive inferior treatment.}

Health workers were asked whether HIV-infected patients were treated better, worse, or the same as other patients in their facility. Slightly more than half of respondents ( 51 percent) felt that these patients receive the same treatment as other patients, 42 percent felt they get better treatment, and only 7 percent felt their treatment is worse. Some health workers noted that HIV is well funded compared to other health conditions and thus HIV-related sections of the health facilities have better access to equipment, supplies, entertainment (e.g., TV sets in PMTCT clinics), and food:

[HIV] Patients are treated well, especially [those with] PTB [pulmonary tuberculosis]; their diet is even better — we give them a packet of milk to supplement their diet. They are discriminated in a better way I would say.

DHMT member, Coast Province
Some providers felt that HIV-positive patients receive greater attention from health workers because of their poorer health condition:

[Attention during clinical rounds] is higher than
for other patients. You have to take more time
with them because they have numerous ailments.
The only problem is the unavailability of drugs.

Health workers, Nyanza Province

At the same time, indications of stigma toward HIV-infected patients emerged. For example, 15 percent of doctors, 12 percent of clinical officers, and 9 percent of registered nurses felt that health workers have a right to refuse to care for an HIV-positive patient. FGDs revealed ways in which these patients were discriminated against, such as reluctance to treat them and isolating them even when medically unnecessary:

\begin{abstract}
Knowingly when a mum says they have taken Nevirapine, midwives do not want to deliver them. They give excuses like 'she is not ready to deliver'so that the mum can deliver when [the midwife] is away. The stigma is there.
\end{abstract}

Female nurse, Coast Province
Table 2 Health workers and AIDS patient management

\begin{tabular}{|c|c|c|c|}
\hline & $\begin{array}{c}\text { Ever cared } \\
\text { for AIDS } \\
\text { patient at } \\
\text { current post^ } \\
\%\end{array}$ & $\begin{array}{c}\text { Ever received } \\
\text { any training in } \\
\text { AIDS patient } \\
\text { management^ } \\
\%\end{array}$ & $\begin{array}{c}\text { Feel adequately } \\
\text { prepared to } \\
\text { manage AIDS } \\
\text { patients } \\
\%\end{array}$ \\
\hline \multicolumn{4}{|l|}{ Cadre } \\
\hline Medical doctor & 97 & 63 & 77 \\
\hline Clinical officer & 79 & 43 & 62 \\
\hline Registered nurse & 85 & 37 & 59 \\
\hline Enrolled nurse & 75 & 26 & 54 \\
\hline \multicolumn{4}{|l|}{ Province } \\
\hline Central & 85 & 41 & 63 \\
\hline Coast & 81 & 25 & 48 \\
\hline Eastern & 81 & 25 & 51 \\
\hline Nairobi & 84 & 47 & 62 \\
\hline North Eastern & 67 & 25 & 71 \\
\hline Nyanza & 92 & 42 & 65 \\
\hline Rift Valley & 70 & 32 & 58 \\
\hline Western & 80 & 41 & 67 \\
\hline All & 79 & 33 & 59 \\
\hline $\begin{array}{l}\text { Number of } \\
\text { respondents }\end{array}$ & 1,494 & 1,494 & 489 \\
\hline
\end{tabular}

^Among all doctors, clinical officers, and nurses; ${ }^{\wedge}$ Among doctors, clinical officers, and nurses who said they had ever been trained in AIDS patient management.
They [HIV-infected patients] are treated differently and put near sluice rooms. They are discriminated. I feel they should mix.

Male clinical officer, Rift Valley

Comments about HIV-related stigma frequently came after the end of the FGDs, when individual health workers would approach the research team quietly and express their observations. Thus it seemed many health workers did not feel comfortable discussing stigma in the context of the larger group meetings but preferred a more confidential setting. The favorable picture presented by the survey data about stigma was often at odds with the private discussions providers had with the research team members. 


\section{Many health workers do not have access to key infection control supplies.}

Nationwide, about three-fourths of health workers had an adequate supply of gloves and sharps disposals. However, only 57 percent reported having an adequate supply of running water, 63 percent an adequate supply of soap, and 67 percent an adequate supply of disinfectant. The situation was similar across the various types of facilities, from hospitals to dispensaries. However, health workers in public sector facilities were less likely to report adequate infection control supplies compared to those in faith-based or other private facilities. Health workers in Western Province reported less availability of most infection control supplies compared to the other provinces. Only a third of participants said there were written guidelines about infection control at their facility.

\section{Health workers were "very concerned" about being infected with HIV at work, but only half knew about PEP.}

Nearly all health workers (94 percent) reported being "very concerned" about getting infected with HIV at work. While 61 percent said they knew what post-exposure prophylaxis (PEP) was, 17 percent of these respondents could not accurately describe it. Thus only 50 percent of the entire study sample had functional knowledge about PEP (i.e., had heard of it and could accurately describe it). Medical doctors were the most informed and enrolled nurses, who comprised nearly half of the sample, were the least informed, with only about a third of this group possessing functional knowledge.

Nearly one in five health workers felt they could have been exposed to HIV at work in the previous 12 months, and half of these had multiple exposures. Among those who reported an incident, had functional knowledge of PEP, and said it was accessible at work or nearby $(n=86)$, only 46 percent of them sought PEP. More than half of those who did not seek PEP said it was either because they lacked information about it, they perceived a lack of confidentiality in accessing it, or they feared the process involved with accessing and taking PEP, which includes HIV testing. FGD participants elaborated on some of these barriers to PEP:

The idea of being tested is fearful to them [health workers].

Female nurse, Coast Province

Health workers are not sensitized to PEP.

Male doctor, Nyanza Province

\section{Many heath workers had an immediate relative who was HIV-positive or who had died of AIDS.}

In the survey, an "immediate relative" was defined as a partner, child, parent, or sibling. As shown in Table 3, 38 percent of all health workers had an immediate relative either currently infected with HIV or who had died of AIDS, with respondents from Nyanza Province (61 percent) and Western Province (52 percent) the most likely to report such a situation. Overall, 17 per-

Table 3 Health workers and familial HIV burden

\begin{tabular}{|c|c|c|}
\hline & $\begin{array}{c}\text { Has immediate } \\
\text { relative infected } \\
\text { with HIV or died } \\
\text { of AIDS } \wedge, \wedge \wedge \\
\%\end{array}$ & 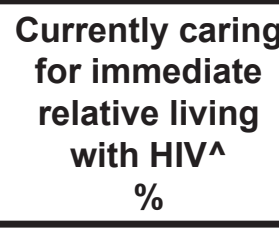 \\
\hline \multicolumn{3}{|l|}{ Sex } \\
\hline Male & 32 & 16 \\
\hline Female & 40 & 18 \\
\hline \multicolumn{3}{|l|}{ Cadre } \\
\hline Doctor & 33 & 18 \\
\hline Clinical officer & 36 & 16 \\
\hline Registered nurse & 37 & 16 \\
\hline Enrolled nurse & 39 & 16 \\
\hline Laboratory staff & 32 & 17 \\
\hline Social worker & 50 & 36 \\
\hline VCT counselor & 42 & 22 \\
\hline Other & 34 & 11 \\
\hline \multicolumn{3}{|l|}{ Province } \\
\hline Central & 36 & 13 \\
\hline Coast & 35 & 10 \\
\hline Eastern & 26 & 9 \\
\hline Nairobi & 38 & 19 \\
\hline North Eastern & 15 & 7 \\
\hline Nyanza & 61 & 37 \\
\hline Rift Valley & 38 & 16 \\
\hline Western & 52 & 32 \\
\hline All respondents & 38 & 17 \\
\hline $\begin{array}{l}\text { Number of } \\
\text { respondents }\end{array}$ & 1,862 & 1,893 \\
\hline
\end{tabular}

^Among all respondents; ^^Figures exclude those who said "don’t know," comprising 1.6 percent of sample 
cent of health workers in the study were currently caring for an HIV-positive relative, including 37 percent from Nyanza Province and 32 percent from Western Province. In the FGDs, some respondents noted that having HIV-positive patients to care for at home negatively impacted health workers at work:

\section{Yes, health workers end up neglecting patients because some of them have HIV-positive relatives at home to care for also.}

Female nurse, Eastern Province

They go home early to take care of patients.

DHMT member, Western Province

\section{Conclusions}

The 2005 Kenya Health Worker Survey revealed that a fourth of providers who conducted some aspect of HIV counseling and testing in clinical settings had not been trained in the procedure(s) they were tasked to undertake. This was particularly the case for doctors and clinical officers, of whom less than half had been trained in counseling and/or testing, yet these were the most likely health workers to perform this service. The results also document a great demand and need for capacity building related to DTC, especially for couple counseling.

Despite gaps in training, health providers who were actively involved in HIV counseling and testing reported following DTC's major steps, including informing the patient before the test was conducted, obtaining consent, and providing or arranging pre- and post-test counseling. However, a limitation of this study is that the data were self-reported. As DTC is rolled out in Kenya, observational studies would be warranted to better understand the extent to which health workers actually follow the guidelines and how well they inform patients about the test and their right to opt out, counsel patients about the results, and maintain patients' confidentiality.

The rapidly changing knowledge and skills required to manage AIDS patients pose major in-service training challenges for the health sector in Kenya. The study found that while 80 percent of the doctors, clinical officers, and nurses had ever cared for an AIDS patient in their current facility, only a third had ever been formally trained in this area. The study also documented that many providers had not read half of the eight national guidelines that could facilitate their work, raising questions about the distribution of the guidelines and the allocation of time to discuss and interpret their content with health workers.

Addressing this large training gap is not an easy issue, given the already heavy workload that health workers endure, and the financial, political, and logistical costs associated with training. While some pre-service training on AIDS patient management is now available in nursing schools and in medical training institutes in Kenya, the class schedule is often quite tight. AIDS is an evolving and demanding disease, and ways to equip providers with the relevant skills to manage it are urgently needed.

Stigma against HIV-infected patients appears to be an issue among health workers in the study. This was not as apparent from the survey findings but emerged more strongly during and after FGDs. Providers reported cases of HIV-positive patients being isolated, being avoided, or receiving differential treatment. Thus, there is a need to address stigma among health workers in a supportive manner that also addresses their concerns about occupational transmission of HIV.

Linked to the existence of stigma is fear of infection: nearly all the providers interviewed in the study said they felt "very concerned" about being infected with HIV at work, yet many did not have adequate supplies of basic infection control items. The study also showed that half the health workers were uninformed about PEP. There is a need to greatly strengthen the infection control environment for health workers in Kenya, and to ensure that they can work without fear of contracting HIV and other infectious diseases.

Because health workers are at continuous risk of occupational exposure to HIV, they should be encouraged to learn their HIV status and supported to make HIV testing routine in health facilities. Two-thirds of health workers surveyed had already been tested, providing an important starting point. However, most of this group had been tested a year or more ago, and could have been exposed subsequently. Therefore efforts to routinize HIV testing should be made to encourage retesting, as well as initial testing by health workers who have never been tested and couple testing and counseling to reach the partners of health workers.

The finding that nearly four out of ten health workers had an immediate relative that was either living with HIV or had died of the disease is of great concern. The figures were as high as 61 percent in Nyanza Province, indicating a large psychosocial burden among health workers there. In this study "immediate" was defined 
as a spouse, child, sibling, or parent, and excluded other relatives outside this tight circle; thus, the impact of HIV on health workers is likely much greater. This means that for many health workers, HIV care does not end in the hospital, but continues at home. Therefore HIV/AIDS workplace programs to help medical personnel cope with the personal impact of this disease are needed. $\boldsymbol{R}$

\section{References}

Central Bureau of Statistics et al. 2004. Kenya Demographic and Health Survey, 2003. Nairobi: Central Bureau of Statistics.

Cheluget, B. et al. 2006. "Evidence for population level declines in adult HIV prevalence in Kenya," Sexually Transmitted Infections 82 (suppl 1): 21-26.

Ministry of Health [Kenya]. 2004. Guidelines for HIV Testing in Clinical Settings. Nairobi: Ministry of Health.

2005. AIDS in Kenya: trends, interventions and impact. Nairobi: Ministry of Health.

NASCOP/Ministry of Health [Kenya]. 2004. Guidelines for HIV Testing in Clinical Settings. Nairobi: Ministry of Health.

Health.

2006. Personal communication. Nairobi: Ministry of

UNAIDS. 2006. 2006 Report on the Global AIDS Epidemic. Geneva: UNAIDS.
The main investigators of the study at NASCOP were Dr. Isaiah Tanui, Mr. Godffrey Baltazar, Mr. John Wanyungu, and Mr. Meshak Ndolo. At CDC-Kenya, the main investigators were Dr. Lawrence Marum and Dr. Mary Mwangi. At Horizons/Population Council, the main investigators were Dr. Karusa Kiragu (Horizons/PATH) and Ms. Susan Kaai (Horizons/Population Council).

The study received financial support from CDC-Kenya under PEPFAR through the NASCOP-CDC Cooperative Agreement No. U62/CCU020906-03-1 and through a CDC contract to Population Council (Horizons) No. S500-4-m-1619. The opinions expressed herein are those of the authors and do not necessarily reflect the views of the Centers for Disease Control and Prevention, Population Council, or the United States Government.

Suggested citation: National AIDS and STD Control Programme; Ministry of Health, Kenya; Centers for Disease Control and Prevention; and Horizons/Population Council. 2007. "Preparedness of Kenyan health workers to deliver HIV/AIDS services," Horizons Research Summary. Washington, DC: Population Council.

\section{Population Council}

Population Council/Horizons

Communications Unit

4301 Connecticut Avenue, NW

Suite 280

Washington, DC 20008
Tel: 202-237-9400

Fax: 202-237-8410

horizons@pcdc.org www.popcouncil.org/horizons
This study received financial support from CDCKenya under the President's Emergency Plan for AIDS Relief (PEPFAR) through the NASCOP-CDC Cooperative Agreement No. U62/CCU020906-03-1 and through a CDC contract to Population Council (Horizons) No. S500-4-m-1619. The opinions expressed herein are those of the authors and do not necessarily reflect the views of the Centers for Disease Control and Prevention, Population Council, or the United States Government. 